\title{
Ruão, Teresa (2006) Marcas e Identidades - Guia da concepção e gestão das marcas comerciais, Porto: Campo das Letras.
}

Madalena Oliveira*

Pode dizer-se que Marcas e Identidades é, em parte, um livro prático, na medida em que ajuda a reflectir sobre estratégias de comunicação e marketing. É, pois, verdade que ele visa, como se lê na introdução, analisar a identidade como "um tema de particular actualidade na gestão de marketing das marcas” (p. 17). Contudo, pode dizer-se também que há neste texto de Teresa Ruão uma certa poética dos objectos. E desse ponto de vista não é apenas de um guia técnico que falamos. É que, ao averiguar a gestão das marcas comerciais, a autora coloca-nos diante da relação afectiva e sensitiva que nos liga às coisas, que é, por sinal, a relação que melhor diz do modo como vivemos o tempo dos objectos, ou, como diz Baudrillard, do modo como "existimos segundo o seu ritmo e em conformidade com a sua sucessão permanente” (1995:15). Este é, por isso, também um livro sobre emoções. Indagando as estratégias de concepção e de divulgação próprias do marketing comercial, em Marcas e Identidades somos confrontados com as marcas que os objectos deixam em nós e, de certo modo, com as marcas que, por causa dos objectos, deixamos uns nos outros.

Depois de Baudrillard, é comum dizer-se que vivemos sob o signo do consumo, cuja referência absoluta seria a felicidade, qual equivalente da salvação (1995:47). Por força da moda, onde, no dizer de Lipovetsky, se dá "a febre moderna de novidades, a celebração do presente social” (1989:17), vivemos, como reconhece Teresa Ruão desde as primeiras páginas, segundo o forte protagonismo assumido pelas marcas (p. 16). Procurar entender o seu modo de funcionamento e, principalmente, o seu papel social, seria, pois, para a autora, pretexto bastante para uma investigação que tem por base a necessidade de perceber "o que pode conduzir a gestão das marcas nos próximos anos” (p. 17).

Se bem que a sua invenção seja anterior ao aparecimento da publicidade e aos meios de comunicação de massas propriamente ditos, é por certo ao desenvolvimento dos media que se deve o triunfo das marcas, cujo estudo nos remete "para a actividade mercantil que cedo se desenvolveu e prosperou" (p. 21). Nascendo da "necessidade dos fabricantes de identificarem a sua oferta, a diferenciarem da concorrência e (...) apelarem ao consumo" (pp. 25-26), as marcas são, em parte, responsáveis pela metamorfose do tempo irreversível em tempo de coisas (Debord,1992), ou não fosse a arma da sua vitória a produção em série de objectos. Mas mais do que um tempo de produção ou um tempo-mercadoria, o tempo das marcas é sobretudo o da sedução das 
coisas, que é, de acordo com Lipovetsky, o tempo da “economia frívola, virada para o efémero e para o último grito" (1989: 221).

Não será, portanto, extraordinário se dissermos, na esteira deste livro, que as marcas se ordenam segundo a lei da sedução. Mais do que um apelo ao consumo, há nelas um apelo à ligação, de que se tem ocupado o marketing do relacionamento, cuja abordagem vê na interacção entre a marca e o consumidor "uma ligação de significação", "um contrato sobretudo simbólico que supõe a transferência de valores, princípios e imagens entre si” (p. 46). Se, inscrevendo as marcas no regime do consumo, poderíamos sugerir que elas estão exclusivamente ligadas a uma ideia de prazer imediato, segundo a proposta do marketing de relacionamento que a autora nos apresenta, dir-se-ia antes que às noções de curto prazo se sobrepõe uma noção de longo prazo, defendendo-se “o estabelecimento de relações quase vitalícias", fundadas na promessa da marca e nos seus sinais de identidade. Visando vínculos duradoiros, ao marketing dos nossos dias convém, por isso, "saber exactamente o que o cliente pretende, atingindo o cliente certo, na altura certa e com o produto certo” (p. 46).

Gerir as marcas "como 'entidades vivas', com a sua própria 'personalidade', e com as quais podemos estabelecer 'relacionamentos'” (p. 30), eis, pois, uma das aspirações do marketing que assim desloca para o domínio comercial uma nova linguagem através da qual se propõe uma espécie de biologização dos objectos. Estando então para os objectos como a personalidade para as pessoas, as marcas operam segundo caracteres constitutivos de uma espécie de ser carismático “capaz de gerar motivação" (p. 59). Mas fazer a "transposição das características humanas para objectos inanimados" (p. 30), supõe considerar que as próprias marcas se tornam desejantes, maquinadoras de paixões. Daí que à identidade das marcas esteja intimamente vinculado um imperativo de comunicação de massas, cujos dispositivos “instalem nos públicos uma percepção clara dos benefícios emocionais e funcionais da marca” (p. 69). Com efeito, "a marca não existe como um fim em si, mas na medida em que representa a oferta organizacional e se projecta aos consumidores” (p. 69), ou seja, na medida em que estabelece ligações.

Geridas numa sociedade de dominante sensológica, como diria Perniola (1993), as marcas comportam, de acordo com a proposta analítica deste livro, atributos emotivos que fazem dos produtos ou empresas que representam objectos quotidianos de afecção. Numa ordem de produção e de consumo, as marcas configuram, na verdade, um deslizamento "de uma lógica da identidade para uma lógica da identificação" (Maffesoli, 1988:244), na medida em que mobilizam para um sentir em conjunto (Perniola, 1993), ou seja, para uma partilha de valores e referências no seio de uma mesma comunidade de consumo. Veículo privilegiado da comunicação de marca, a publicidade tem em todo este processo uma performance inalienável: a ela compete "proporcionar informação sobre uma ou mais características e atributos dos produtos, num contexto certamente persuasivo mas nunca enganoso" (p. 79). Mas a comunicação de marca não é apenas devedora da publicidade. Referindo-se, no final do capítulo 4, aos meios alternativos, Teresa Ruão anota, em síntese, o papel da promoção de vendas, das relações públicas 
e dos patrocínios (p. 83) como modos de as marcas procurarem "soluções criativas e inovadoras, que façam chegar as mensagens aos públicos-alvo, mas que assegurem também consistência e coerência de sentidos” (p. 86).

Dizíamos antes que Marcas e Identidades é também um livro de emoções. Tínhamos nesse momento a ideia de que as marcas “agem” como estímulos dos nossos sentidos, despertando em nós sobretudo um desejo pela compra e pela propriedade dos objectos. Mas, depois de termos dito que as marcas são da ordem da sedução, será seguro que não é apenas numa arqueologia dos efeitos que encerramos o capital sensitivo das marcas. É que, se "gerir a marca significa administrar o seu conjunto de activos" (p. 97), então é tarefa dos marketers "criar para os produtos personalidades fortemente relacionadas com o carácter próprio ou imaginado dos seus consumidores-alvo” (p. 100). Dito de outro modo, gerir a marca é tomá-la a ela própria como emoção e, portanto, como sujeito de uma erótica, cujo "carácter e demais aspectos intangíveis resultam da comunicação que se desenvolve de forma planeada com os consumidores” (p. 101).

Investindo os objectos de sex-appeal, as marcas estão então para lá do sentido puramente económico. Elas actuam ainda, ou sobretudo, como "expoente cultural de classe" (Baudrillard, 1995:91), sendo a sua dimensão simbólica o que de verdade parece revelar o seu êxito, ou por outra, o seu carisma. É justamente numa das mais carismáticas marcas portuguesas (p. 105) que Teresa Ruão fixa o olhar empírico deste guia cujo objectivo estava traçado desde o início: “averiguar a identidade da marca Vista Alegre clássica, analisando as suas funções de representação e apelo no marketing das marcas", por um lado, e por outro, "reconhecendo os seus traços caracterizadores e percebendo de que forma são usados para representar a promessa da empresa e apelar ao consumo" (p. 18).

Fundada em 1824 de acordo com provisão régia de D. João VI, a Vista Alegre é, no contexto da indústria portuguesa, um caso não só de identidade como também de identificação. Quase à beira de dois séculos de história, poderá dizer-se que a Vista Alegre se inscreve no imaginário português como uma das marcas mais significativas na produção de "louça, porcelana, vidraria e processos químicos" (como se previa no projecto inicial de criação da fábrica), mas também - não será excessivo dizê-lo - como uma das marcas da identidade nacional. Por isso, enquanto marca comercial, a Vista Alegre presta-se particularmente bem a esta pesquisa desenvolvida sob o signo de Marcas e Identidades. Num estudo de caso, que busca na análise de conteúdo um instrumento de diagnóstico da identidade da marca em questão, a autora orienta-se por uma pergunta inicial abreviada nestes termos: "Quais os traços caracterizadores da identidade da marca Vista Alegre clássica e de que forma é usada para representar a oferta organizacional e apelar aos consumidores?” (p. 112). A esta questão, a investigadora associou uma codificação de unidades semânticas agrupadas em nove categorias temáticas de identidade: tradição, família, prestígio, modernidade, vitalidade, qualidade, estabilidade, internacionalização e Portugal (p. 128). Da análise efectuada, inferiu Teresa Ruão que "a identidade nuclear da marca Vista Alegre (...) se define à volta de cinco traços principais”: o respeito pela tradição histórica e de negócio da 
empresa; a afirmação permanente do prestígio e preocupação constante com a sua protecção; a capacidade de modernização e renovação da oferta da empresa; a forte ligação a Portugal, à sua história e cultura e a importância da continuidade familiar na liderança da empresa (p. 135).

Apesar dos pontos de debilidade, que dizem respeito à hibridez da identidade da sub-marca Ema, à redução do conceito de identidade da marca Vista Alegre a uma dimensão sobretudo visual e ao fraco controlo da distribuição (p.141), a autora concluiu que "a relação que esta marca estabelece hoje com os consumidores, sendo uma ligação estável, porque equilibrada, é também dinâmica e jovem” (p.159). É, porém, certo que 150 anos de monopólio no fabrico de porcelana em Portugal terão contribuído para a "identidade de excelência da marca", uma identidade que "reside numa matriz com características bem definidas, coerentes com o passado e passíveis de orientação para o futuro" (p. 162). O mesmo século e meio de história terá contribuído assim para um “bem-estar mensurável por objectos” (Baudrillard, 1995:47), objectos que se manipulam sempre "como signos que distinguem o indivíduo" (ibidem: 60). Na elegância das colecções, na delicadeza da loiça, na íntima conexão com a história de Portugal, a Vista Alegre é hoje a marca de uma memória de nacionalidade que, conjugada com "a qualidade, estabilidade e a exclusividade da sua oferta" e com a "notoriedade e reputação" dos seus produtos (p. 163), é ainda signo de um patriotismo que revela uma certa poética do olhar. Fixado nas inscrições da porcelana, este olhar revela não apenas a marca da identidade da empresa, mas sobretudo a marca da identidade de um país, de uma cultura e ainda das idiossincrasias de um povo. Por isso dizíamos que o livro de Teresa Ruão seria também um livro sobre as marcas que os objectos deixam em nós. E porque todos somos iguais apenas perante os objectos enquanto valor de uso, "mas não diante dos objectos enquanto signos e diferenças" (Baudrillard, 1995:91), as marcas de que nos fala este texto são necessariamente também as que nos ligam aos outros em relações cada vez mais decididas pelo marketing.

\section{Referências bibliográficas}

BAUDRILLARD, Jean (1995) A Sociedade de Consumo, Lisboa: Edições 70.

DEBORD, Guy (1992) La Société du spectacle, Paris : Éditions Gallimard.

LIPOVETSKY, Gilles (1989) O Império do Efémero - A moda e o seu destino nas sociedades modernas Lisboa: Publicações Dom Quixote.

MAFFESOLI, Michel (1988a) "A ética da estética: Homo Estheticus”, in Revista de Comunicação \&o Linguagens, n. ${ }^{\circ} 6 / 7$.

PERNIOLA, Mario (2004) O Sex-Appeal do Inorgânico, Coimbra: Ariadne Editora.

PERNIOLA, Mario (1993) Do Sentir, Lisboa: Editorial Presença. 